\title{
Dyslipidemia and Associated Risk Factors among Nigerians with Hypertension
}

\author{
Olufisayo Gabriel Ayoade ${ }^{\mathrm{a}}$ Idongesit Umoh ${ }^{\mathrm{b}}$ Collins Amadi ${ }^{\mathrm{a}}$ \\ ${ }^{a}$ Department of Chemical Pathology, University of Uyo Teaching Hospital, Uyo, Nigeria; \\ ${ }^{\mathrm{b}}$ Department Internal Medicine, University of Uyo Teaching Hospital, Uyo, Nigeria
}

\section{Keywords}

Dyslipidemia · Hypertension · Cardiovascular disease

\begin{abstract}
Background: Abnormalities in serum lipids and lipoprotein levels with essential hypertension are vital independent causal factors for atherosclerotic cardiovascular disease (ASCVD). The coexistence of these factors has a synergistic effect in heightening the risk of cardiovascular events. The aim of the study was to evaluate the pattern of dyslipidemia among hypertensives and to determine some of its correlations in patients attending a tertiary hospital in South South Nigeria. Methods: This was a cross-sectional study conducted on 544 eligible hypertensive patients attending the Cardiology Clinic, University of Uyo Teaching Hospital (UUTH), Uyo, Nigeria, over a period of 6 months. Fasting lipids, total cholesterol (TC), triglycerides (TG), high-density lipoprotein cholesterol (HDL-C), and low-density lipoprotein cholesterol (LDL-C) were evaluated. Results: Overall, $60.0 \%$ of the hypertensive patients had dyslipidemia, with $43.4 .0 \%$ having high TC, 30.3\% high LDL-C, 20.8\% elevated TG, and 12.9\% low $\mathrm{HDL}-\mathrm{C}$, respectively. There was a significant relationship between gender and lipoproteins, with women having significantly higher lipoproteins (TC, HDL-C, LDL-C, and non-HDLC) than men. Women also had more measures of obesity
\end{abstract}

with a higher body mass index and waist circumference. TC and non-HDL had a significant association with both systolic and diastolic blood pressure (BP). Altogether, $43.4 \%$ of the hypertensives had poorly controlled BP and significantly higher atherogenic lipoproteins (TC, LDL-C, and non-HDL-C). Conclusion: This study has demonstrated the relatively high prevalence of dyslipidemia among hypertensive patient in this population. High plasma TC is the most dominant pattern of dyslipidemia. Hypertensive patients with poorly controlled BP have worse atherogenic lipoprotein values and are more likely predisposed to ASCVD.

(c) 2020 The Author(s)

Published by S. Karger AG, Basel

\section{Introduction}

Dyslipidemia and hypertension are the 2 major independent risk factors for atherosclerotic cardiovascular disease (ASCVD). ASCVD accounts for $>80 \%$ of all deaths and disability in low- and middle-income countries and results in a high economic loss and burden [1, 2]. The combined effects of the above 2 vital factors have been shown to be multiplicative, meaning the risk of coronary heart disease is greater than the sum of the risks of each component occurring alone $[3,4]$. About $50-80 \%$ of hypertensives have been reported to have plasma lipid ab-

$\begin{array}{ll}\text { karger@karger.com } & \text { (c) 2020 The Author(s) } \\ \text { Published by S. Karger AG, Basel } & \text { Karger } \\ \text { This article is licensed under the Creative Commons Attribution- } & \text { NonCommercial-NoDerivatives 4.0 International License (CC BY- } \\ \text { NC-ND) (http://www.karger.com/Services/OpenAccessLicense). } \\ \text { Usage and distribution for commercial purposes as well as any dis- } \\ \text { tribution of modified material requires written permission. }\end{array}$


normalities. The prevalence of hypertension has been steadily on the increase in Nigeria, as in most African countries, due to rapid urbanization, unhealthy lifestyle changes, and a reduced burden of infectious diseases. The prevalence of hypertension in Nigeria progressively increased, from $10.1-13.3 \%$ in the late 1960 s to $38.8-44.5 \%$ [5]. In 2010, there were 20 million cases in Nigeria, and this figure has been projected to rise to 39.1 million by 2030 [5].

Dyslipidemia plays a role in endothelial dysfunction which is central to the pathogenesis of atherosclerosis, thrombosis, insulin resistance, and hypertension. Triglyceride (TG)-rich lipoproteins and low-density lipoprotein cholesterol (LDL-C) have been shown to be toxic to endothelial cells, but high-density lipoprotein cholesterol (HDL-C) is protective [6]. High levels of serum cholesterol are known to increase the risk of developing macrovascular complications such as coronary heart disease and stroke [7]. A rising trend of serum cholesterol TG, LDL-C, and very-low-density lipoprotein (VLDL), along with a fall in HDL-C has been found to be associated with the severity of hypertension [7].

The associations between blood pressure (BP) and the risk of stroke and coronary heart disease are well established. Similarly, there are also strong associations between serum cholesterol and the risk of coronary heart disease. The Framingham Heart Study data on the hypertensive population reported that $>80 \%$ had at least 1 additional CVD risk factor and that these risk factors were predominantly atherogenic in nature. Studies have consistently indicated that hypertension and hypercholesterolemia frequently coexist, causing what is known as dyslipidemic hypertension [8].

Current guidelines for the management of dyslipidemia suggest screening in early adulthood. Early detection of lipid disorders will help in applying the proper treatment modalities such as implementing therapeutic lifestyle changes in preventing adverse cardiovascular outcomes. Early screening also decreases the risk of any future cardiovascular event and reduces the risks of any associated cardiovascular risk factors. Guidelines, such as those from the Adult Treatment Panel (ATP III), the US Preventive Services Task Force, the American College of Cardiology/American Heart Association (ACC/AHA), and the American Association of Clinical Endocrinologists (AACE) 2017, suggest screening for abnormal lipid profiles in adults $>20$ years of age [9-11]. Even though there is no published national guideline in Nigeria for the management of dyslipidemia, there has been sufficient evidence of early screening in this environment [12].
The relationship between dyslipidemia and the traditional cardiovascular risk factors, such as obesity and hypertension, has been clearly demonstrated in several epidemiological studies $[13,14]$. The indicators or measures of the risk factors body mass index (BMI) and waist circumference (WC) for obesity have been shown to be a strong predictor of abnormal lipids and lipoproteins [14].

The risk of stroke and myocardial infarction has been shown to be significantly reduced by lipid-lowering drugs, so identifying hypertensive patients and the pattern of dyslipidemia in this population is key to successful management. Dyslipidemia in hypertensives has been demonstrated to vary according to the ethnic, socioeconomic, and cultural characteristics of population groups [15].

The pattern of lipid abnormalities among hypertensives and its impact on CVD risk in Uyo, South South Nigeria, has not been well characterized. Moreover, to the best of our knowledge, no study has focused on abnormal lipid pattern and possible risk factors for dyslipidemia among hypertensives. The purpose of this study was to estimates the prevalence and pattern of dyslipidemia among hypertensives and establish the relationship of lipid markers and other cardiovascular risk factors.

\section{Methods}

\section{Study Design and Site}

This was a cross-sectional study done at the University of Uyo Teaching Hospital (UUTH) over a period of 6 months, between April and October 2019. UUTH is a tertiary medical facility located in Akwa Ibom State, South South Nigeria. The hospital is a major referral center for both the private, primary, and secondary health care facilities in this state and adjoining states in Nigeria. We recruited 544 hypertensive patients (345 females and 196 males) attending the Cardiology Clinic during the study period.

Eligibility Criteria

We included all diagnosed hypertensives attending cardiology clinic. We excluded diabetics and patients on antihypertensives and lipid-lowering agents.

\section{Measurements}

$\mathrm{BP}$ was measured in a sitting position using a standard mercury sphygmomanometer after 5 min of rest. Body weight and height were measured with a portable standardized weighing scale and a stadiometer, respectively. BMI was calculated. WC measurements were then taken with a tape measure at a point midway between the inferior margin of the lower-most rib and the iliac crest in a horizontal plane. Fasting serum lipid profile was determined using blood obtained following an overnight (10-12 h) fast. Total 
Table 1. Baseline characteristics of study participants

\begin{tabular}{lcccr}
\hline & $\begin{array}{l}\text { Total } \\
(n=544)\end{array}$ & $\begin{array}{l}\text { Male } \\
(n=199)\end{array}$ & $\begin{array}{l}\text { Female } \\
(n=345)\end{array}$ & $p$ value \\
\hline Age, years & $56(12)$ & $59(12)$ & $54(12)$ & $<0.001$ \\
Systolic BP, mm Hg & $131(21)$ & $132(21)$ & $131(21)$ & 0.536 \\
Diastolic BP, mm Hg & $81(14)$ & $82(13)$ & $81(14)$ & 0.519 \\
BMI, kg/m 2 & $30.1(6.3)$ & $27.0(5.2)$ & $31.8(6.2)$ & $<0.001$ \\
WC, cm & $99(14)$ & $96.7(13.8)$ & $99.8(14.7)$ & 0.014 \\
TC, mmol/L & $5.04(1.25)$ & $4.81(1.23)$ & $5.18(1.23)$ & 0.001 \\
TG, mmol/L & $1.29(0.60)$ & $1.32(0.68)$ & $1.27(0.54)$ & 0.382 \\
HDL-C, mmol/L & $1.53(0.48)$ & $1.44(0.44)$ & $1.58(0.49)$ & 0.001 \\
LDL-C, mmol/L & $2.88(1.14)$ & $2.73(1.13)$ & $2.97(1.14)$ & 0.020 \\
Non-HDL-C, mmol/L & $3.51(1.17)$ & $3.36(1.16)$ & $3.60(1.16)$ & 0.021 \\
TC/HDL-C ratio & $3.63(2.28)$ & $3.53(1.12)$ & $3.68(2.73)$ & 0.458 \\
\hline
\end{tabular}

Values are expressed as mean (SD). ${ }^{*} p<0.05$. LDL-C, low-density lipoprotein cholesterol; HDL-C, high-density lipoprotein cholesterol; BP, blood pressure; TG, triglycerides; BMI, body mass index; WC, waist circumference; TC, total cholesterol.

Table 2. Prevalence of dyslipidemia based on age and gender

\begin{tabular}{|c|c|c|c|c|c|}
\hline & $\begin{array}{l}\text { High TC } \\
(\geq 5.20)\end{array}$ & $\begin{array}{l}\text { High TG } \\
(\geq 1.70)\end{array}$ & $\begin{array}{l}\text { Low HDL-C } \\
(<1.04)\end{array}$ & $\begin{array}{l}\text { High LDL-C } \\
(\geq 3.37)\end{array}$ & $\begin{array}{l}\text { High TC/HDL-C } \\
(\geq 5)\end{array}$ \\
\hline Total & $236(43.4)$ & $113(20.8)$ & $70(12.9)$ & $165(30.3)$ & $58(10.7)$ \\
\hline Male & $72(13.2)$ & $40(35.4)$ & $34(6.3)$ & $53(9.6)$ & $21(3.9)$ \\
\hline Female & $164(30.2)$ & $73(64.6)$ & $36(6.6)$ & $112(20.7)$ & $37(6.8)$ \\
\hline$p$ value & 0.358 & 0.204 & 0.065 & 0.599 & 0.192 \\
\hline \multicolumn{6}{|l|}{ Age } \\
\hline $25-34$ years & $10(4.2)$ & $4(3.5)$ & $6(8.6)$ & $8(4.8)$ & $6(10.3)$ \\
\hline $35-44$ years & $26(11.0)$ & $12(10.6)$ & $4(5.7)$ & $18(10.9)$ & $3(5.2)$ \\
\hline $45-54$ years & $56(23.7)$ & $27(23.9)$ & $18(25.7)$ & $34(20.6)$ & $11(19.0)$ \\
\hline 55-64 years & $87(36.9)$ & $45(39.8)$ & $23(32.9)$ & $63(38.2)$ & $20(34.5)$ \\
\hline$\geq 65$ years & $57(24.2)$ & $25(22.1)$ & $19(27.1)$ & $42(25.5)$ & $18(31.0)$ \\
\hline$p$ value & 0.448 & 0.806 & 0.375 & 0.231 & 0.090 \\
\hline
\end{tabular}

Values are expressed as $n$ (\%). The lipoprotein cut-off values are all in mmol/L. LDL-C, low-density lipoprotein cholesterol; HDL-C, high-density lipoprotein cholesterol; TG, triglycerides; TC, total cholesterol.

cholesterol (TC), TG, and HDL-C were analyzed using an enzymatic method on an automated chemistry analyzer, Selectra Pro M (ELITech Group, The Netherlands). Non-HDL-C was calculated as TC minus HDL-C and LDL-C was determined using the Friedewald formula.

\section{Definition of Terms}

Dyslipidemia was defined according to the National Cholesterol Education Program (NCEP) ATP III [9] as a raised TG level of $\geq 1.7 \mathrm{mmol} / \mathrm{L}$, reduced HDL-C of $<1.04 \mathrm{mmol} / \mathrm{L}$, an LDL-C level of $>3.37 \mathrm{mmol} / \mathrm{L}$, and/or a TC level of $\geq 5.2 \mathrm{mmol} / \mathrm{L}$.

Hypertension was defined as systolic BP (SBP) $140 \mathrm{~mm} \mathrm{Hg}$ and/or diastolic BP (DBP) $90 \mathrm{~mm} \mathrm{Hg}$, using criteria from the Seventh Report of the Joint National Committee on Prevention, Detection, Evaluation and Treatment of Hypertension [15].

Dyslipidemia and Associated Risk Factors among Nigerians with Hypertension
Controlled BP is an SBP $<140 \mathrm{~mm} \mathrm{Hg}$ and a DBP $<90 \mathrm{~mm} \mathrm{Hg}$ which is controlled by antihypertensive drug(s) and/or nonpharmacological methods.

Uncontrolled or poorly controlled BP is an SBP $\geq 140 \mathrm{~mm} \mathrm{Hg}$ and/or DBP $\geq 90 \mathrm{~mm} \mathrm{Hg}$.

\section{Statistical Analysis}

Data was analyzed using SPSS v20 software (SPSS Inc., Chicago, IL, USA). Simple descriptive statistics were used to present the demographic characteristics of the study participants. Continuous variables were presented as mean \pm SD and were compared using the Student $t$ test. Categorical variables were presented as proportions, and the $\chi^{2}$ test was used to compare them. Other associations were evaluated with Pearson's correlation coefficient. A $p$ value < 0.05 was considered statistically significant. 


\section{Results}

A total of 544 hypertensive patients who attended the Cardiology Clinic, UUTH, between April and October 2019 were recruited to this study. The age range was $27-$ 80 years; $63 \%$ were female $(n=345)$ with a mean age of 54 years and $37 \%$ were male with a mean age of 59 years. There was no significant difference in BP and plasma TG between the genders, but women had significantly higher lipoproteins (TC, HDL-C, LDL-C, and non-HDL-C). Women also had more measures of obesity, with a higher BMI and WC than men (Table 1).

Overall, $60 \%$ of hypertensive patient had dyslipidemia and at least 1 abnormal lipoprotein. Table 2 shows the dyslipidemia based on age and gender. The most prevalent abnormal lipid fraction was high TC, which occurred in $43.4 \%$ of the study population, more in females and the age group of 55-64 years. LDL-C was elevated in about one-third, within the same age group and with the same gender dominance as TC. There was high TG and low HDL-C in 20.8 and $12.9 \%$ of the study population, respectively.

There was a significant relationship between gender and lipoproteins. The women had significantly higher lipoprotein levels than the men (Table 3). TC and nonHDL-C had a significant association with both SBP and DBP. It was observed that more than half of the study population were obese (BMI $\geq 30)$ and $65.6 \%$ had a WC $\geq 102 \mathrm{~cm}$, also significantly more women than men (Table $4 \mathrm{~A})$. Most of the subjects had good BP control; only $43.4 \%$ had poorly controlled BP. In the men, TC, LDL-C, and non-HDL-C were significantly higher in those with poorly controlled $\mathrm{BP}$ than those whose $\mathrm{BP}$ was well controlled (Table 4B).

\section{Discussion}

This study was designed to determine the pattern of dyslipidemia among hypertensive patients attending the Cardiology Clinic, UUTH, Uyo, and also investigate the association with cardiovascular risk factors (indicators/ measures of obesity). Our results showed a high prevalence of dyslipidemia with higher TC, TG, and LDL-C values, i.e., more than the respective cut-off values, with about $60 \%$ of the patients fulfilling at least 1 criterion for dyslipidemia according to the NCEP ATP III guideline for the detection, evaluation, and management of dyslipidemia [9]. This is consistent with reported rates of dyslipidemia among hypertensives, which has ranged
Table 3. Association of plasma lipoproteins with other cardiovascular risk factor

\begin{tabular}{|c|c|c|}
\hline & $\begin{array}{l}\text { Pearson's correlation } \\
\text { coefficient }\left(r^{2}\right)\end{array}$ & $p$ value \\
\hline \multicolumn{3}{|l|}{ TC } \\
\hline Age & -0.10 & 0.813 \\
\hline Gender & 0.146 & $0.001^{*}$ \\
\hline BMI & 0.065 & 0.128 \\
\hline WC & 0.032 & 0.450 \\
\hline SBP & 0.657 & $<0.001^{*}$ \\
\hline DBP & 0.111 & 0.009 \\
\hline \multicolumn{3}{|l|}{ TG } \\
\hline Age & 0.028 & 0.509 \\
\hline Gender & -0.038 & 0.382 \\
\hline BMI & 0.043 & 0.544 \\
\hline WC & 0.005 & 0.095 \\
\hline SBP & 0.086 & 0.046 \\
\hline DBP & 0.084 & 0.051 \\
\hline \multicolumn{3}{|l|}{ HDL-C } \\
\hline Age & -0.039 & 0.360 \\
\hline Gender & 0.139 & $0.001^{*}$ \\
\hline BMI & 0.114 & $0.008^{*}$ \\
\hline WC & 0.085 & $0.047^{*}$ \\
\hline SBP & 0.059 & 0.170 \\
\hline DBP & 0.018 & 0.668 \\
\hline \multicolumn{3}{|l|}{ LDL-C } \\
\hline Age & 0.014 & 0.748 \\
\hline Gender & 0.100 & $0.020^{*}$ \\
\hline BMI & -0.019 & 0.662 \\
\hline WC & -0.028 & 0.509 \\
\hline SBP & 0.078 & 0.069 \\
\hline DBP & 0.082 & 0.057 \\
\hline \multicolumn{3}{|c|}{ Non-HDL-C } \\
\hline Age & 0.005 & 0.905 \\
\hline Gender & 0.099 & $0.021^{*}$ \\
\hline BMI & 0.023 & 0.593 \\
\hline WC & 0.002 & 0.992 \\
\hline SBP & 0.114 & $0.008^{*}$ \\
\hline DBP & 0.111 & $0.009 *$ \\
\hline
\end{tabular}

$* p<0.05$. LDL-C, low-density lipoprotein cholesterol; HDL-C, high-density lipoprotein cholesterol; BP, blood pressure; TG, triglycerides; BMI, body mass index; WC, waist circumference; TC, total cholesterol.

between 49.5 and $78.9 \%$ in several studies worldwide [16-18].

The prevalence rate of $60 \%$ is comparable to the study by Akintunde et al. [19] who reported $58.9 \%$ in South West Nigeria, and by Adamu et al. [20] who reported $64.1 \%$ in North Central Nigeria. Dyslipidemia, as demonstrated by this study, increases with age and is prevalent in subjects between 55 and 64 years of age and in both genders. Ericsson et al. [21] hypothesized that hyperlipidemia 
Table 4.

A BMI, WC, and BP of hypertensive patients

\begin{tabular}{llcc}
\hline & $\begin{array}{l}\text { Total }(n=544), \\
n(\%)\end{array}$ & $\begin{array}{l}\text { Males }(n=199), \\
n(\%)\end{array}$ & $\begin{array}{l}\text { Females }(n=345), \\
n(\%)\end{array}$ \\
\hline BMI & & & \\
$\quad$ Normal $(\leq 25)$ & $123(22.6)$ & $76(14.0)$ & $47(8.6)$ \\
$\quad$ Overweight $(25-29.9)$ & $133(24.4)$ & $61(11.2)$ & $72(13.2)$ \\
$\quad$ Obese $(\geq 30)$ & $288(52.9)$ & $62(11.4)$ & $226(41.5)$ \\
WC & & $135(24.8)$ & $52(9.6)$ \\
$\quad<102 \mathrm{~cm}$ (men)/88 cm (women) & $187(34.4)$ & $64(11.8)$ & $293(53.9)$ \\
$\quad \geq 102 \mathrm{~cm}$ (men)/88 cm (women) & $357(65.6)$ & $113(20.8)$ & $194(35.7)$ \\
BP & $307(56.4)$ & $86(15.8)$ & $151(27.8)$ \\
$\quad$ Well-controlled & $237(43.6)$ & &
\end{tabular}

B Lipid profiles of male and female hypertensive patients with well-controlled or poorly controlled BP

\begin{tabular}{|c|c|c|c|c|c|c|}
\hline & \multicolumn{3}{|l|}{ Males } & \multicolumn{3}{|l|}{ Females } \\
\hline & $\begin{array}{l}\text { well-controlled } \\
(n=113)\end{array}$ & $\begin{array}{l}\text { poorly controlled } \\
(n=86)\end{array}$ & $p$ value & $\begin{array}{l}\text { well-controlled } \\
(n=194)\end{array}$ & $\begin{array}{l}\text { poorly controlled } \\
(n=151)\end{array}$ & $p$ value \\
\hline TC & $4.59(1.19)$ & $5.09(1.25)$ & $0.005^{*}$ & $5.17(1.21)$ & $5.21(1.27)$ & 0.771 \\
\hline $\mathrm{TG}$ & $1.26(0.64)$ & $1.40(0.73)$ & 0.164 & $1.24(0.50)$ & $1.31(0.59)$ & 0.226 \\
\hline HDL-C & $1.44(0.48)$ & $1.45(0.40)$ & 0.899 & $1.59(0.46)$ & $1.56(0.52)$ & 0.550 \\
\hline LDL-C & $2.59(1.08)$ & $2.93(1.16)$ & $0.035^{*}$ & $2.96(1.13)$ & $2.99(1.15)$ & 0.812 \\
\hline Non-HDL-C & $3.15(1.08)$ & $3.64(1.22)$ & $0.003^{*}$ & $3.57(1.17)$ & $3.64(1.15)$ & 0.576 \\
\hline
\end{tabular}

$* p<0.05$. LDL-C, low-density lipoprotein cholesterol; HDL-C, high-density lipoprotein cholesterol; BP, blood pressure; TG, triglyceride; TC, total cholesterol; BMI, body mass index; WC, waist circumference.

with advancing age can be due to a reduced catabolism and clearance of plasma lipoproteins. We also observed that women had more abnormalities in serum lipids than men, especially in the age group of 55-65 years. This is consistent with large-scale studies such as the Framingham Heart Study and the National Health and Nutrition Examination Survey (NHANES) [4, 22]. Studies has shown that postmenopausal women have proatherogenic lipid profiles in comparison to age-matched men; this is due to the decline in the influence of sex steroids that mediates sex differences in plasma lipid homeostasis [22, 23].

The most common type of dyslipidemia observed in our study population was hypercholesterolemia. This was also reported by Osuji et al. [17] in South East Nigeria. However, some other studies in the South West have reported mostly low HDL-C as the predominant type [19, $24]$. Social economic status, dietary pattern, and other environmental factors also differ widely according to ethnicity and are likely contributors to the observed disparities. We found a significant relationship between TC and both SBP $(p<0.001)$ and DBP $(p=0.009)$. A similar finding was reported by Okpara and Adediran [25]. Elevated TC is known to increase the risk of macrovascular complications such as CVD and stroke. Despite comparable TC, TG, and LDL-C results in other studies in different parts of the country, HDL-C in our study population was higher. However, elevated HDL-C was also observed by Onwubuya et al. [26] in the South East. The cause for this is not known, although it has been suggested that alcohol increases HDL-C by facilitating the transport of apolipoprotein A1 [27].

This study showed that most of the hypertensive patients (56\%) had poorly controlled BP and $44 \%$ had wellcontrolled BP. The hypertensives with poorly controlled BP have worse atherogenic lipoprotein values. Hypertension and lipid abnormalities are well known to frequently coexist and synergize to be risk factors for CVD. The coexistence of increased BP and lipid abnormalities has many clinical implications and should be properly monitored and evaluated in the management of hypertension. 
In our study population, $77.4 \%$ were either overweight or obese, and $>65 \%$ had abdominal obesity. Obesity and consequent insulin resistance are major underlying factors in the pathogenesis of both hypertension and dyslipidemia. There is a strong association among these metabolic derangements forming the core of the diagnosis of metabolic syndrome. Lipid abnormalities, a characteristic of metabolic syndrome, have been found to predict hypertension, and it has also been shown in cohort studies that dyslipidemia in apparently healthy individuals leads to hypertension [25].

The main limitation of our study was the fact that it was hospital-based, making it difficult to generalize our findings to reflect the whole country. Also, it was a crosssectional study, and thus cannot be used to predict some of the causal relationships indicated. We therefore recommend conducting more prospective studies with larger sample sizes.

\section{Conclusion}

The prevalence of dyslipidemia in our study population was high and increased with age. The most common dyslipidemia was hypercholesterolemia, and this occurred significantly more in women. Obesity was also more prevalent among female hypertensives. Patients with poorly controlled BP had significantly higher atherogenic lipoproteins and were thus more predisposed to developing CVD. These findings highlight the need to promote screening of hypertensive patients. It is there- fore recommended that, in patients with hypertension, determination of the lipid and lipoprotein levels should complement other investigations.

\section{Acknowledgement}

We are thankful to Blessing Umoh, for her help in data collection. We also acknowledge the resident doctors in the Chemical Pathology and Cardiology Unit, Internal Medicine, for their assistance.

\section{Statement of Ethics}

The authors had the approval from the University of Uyo Teaching Hospital Institution Health Research Ethical Committee.

\section{Conflict of Interest Statement}

The authors have no conflicts of interest to disclose.

\section{Funding Sources}

The authors did not receive funding from any source.

\section{Author Contributions}

O.G.A.: conception, analysis, manuscript drafting, data analysis, literature review and final write up of the article. I.U.: design, data collection, literature review and critical analysis. C.A.: design, data collection, manuscript drafting, ethical approval, critical analysis.

\section{References}

1 Reddy KS. Cardiovascular disease in nonWestern countries. N Engl J Med. 2004 Jun; 350(24):2438-40.

2 Murray CJ, Lopez AD. Global mortality, disability, and the contribution of risk factors: Global Burden of Disease Study. Lancet. 1997 May;349(9063):1436-42.

3 Stamler J, Wentworth D, Neaton JD. Prevalence and prognostic significance of hypercholesterolemia in men with hypertension. Prospective data on the primary screenees of the Multiple Risk Factor Intervention Trial. Am J Med. 1986 Feb;80(2A):33-9.

4 Castelli WP, Anderson K. A population at risk. Prevalence of high cholesterol levels in hypertensive patients in the Framingham Study. Am J Med. 1986 Feb;80(2A):23-32.

5 Ogah OS, Okpechi I, Chukwuonye II, Akinyemi JO, Onwubere BJ, Falase AO, et al. Blood pressure, prevalence of hypertension and hypertension related complications in Nigerian Africans: a review. World J Cardiol. 2012 Dec;4(12):327-40.

6 Albucher JF, Ferrieres J, Ruidavets JB, Guiraud-Chaumeil B, Perret BP, Chollet F. Serum lipids in young patients with ischaemic stroke: a case-control study. J Neurol Neurosurg Psychiatry. 2000 Jul;69(1):29-33.

7 Nayak P, Panda S, Thatoi PK, Rattan R, Mohapatra S, Mishra PK. Evaluation of Lipid Profile and Apolipoproteins in Essential Hypertensive Patients. J Clin Diagn Res. 2016 Oct;10(10):BC01-04.

8 Kannel WB. Fifty years of Framingham Study contributions to understanding hypertension. J Hum Hypertens. 2000 Feb;14(2):8390.

9 Expert Panel on Detection, Evaluation, and Treatment of High Blood Cholesterol in Adults. Executive Summary of The Third Re- port of The National Cholesterol Education Program (NCEP) Expert Panel on Detection, Evaluation, And Treatment of High Blood Cholesterol in Adults (Adult Treatment Panel III). JAMA. 2001 May;285(19):2486-97.

10 Jellinger PS, Handelsman Y, Rosenblit PD, Bloomgarden ZT, Fonseca VA, Garber AJ, et al. American Association of Clinical Endocrinologists and American College of Endocrinology guidelines for management of dyslipidemia and prevention of cardiovascular disease. Endocr Pract. 2017 Apr;23 Suppl 2:1-87.

11 Stone NJ, Robinson J, Lichtenstein AH, et al. 2013 ACC/AHA guideline on the treatment of blood cholesterol to reduce atherosclerotic cardiovascular risk in adults: a report of the American College of Cardiology/American Heart Association task force on practice guidelines. J Am Coll Cardiol. 2014 Jul 1; 63(25 Pt B):2889-934. 
12 Oguejiofor OC, Onwukwe $\mathrm{CH}$, Odenigbo CU. Dyslipidemia in Nigeria: prevalence and pattern. Ann Afr Med. 2012 Oct-Dec;11(4): 197-202.

13 Nguyen NT, Magno CP, Lane KT, Hinojosa MW, Lane JS. Association of hypertension, diabetes, dyslipidemia, and metabolic syndrome with obesity: findings from the $\mathrm{Na}-$ tional Health and Nutrition Examination Survey, 1999 to 2004. J Am Coll Surg. 2008 Dec;207(6):928-34.

14 Brown CD, Higgins M, Donato KA., Rohde FC., Garrison R, Obarzanek et al. Body Mass Index and the Prevalence of Hypertension and Dyslipidemia. Obes Res. 2000 Dec;8(9): 605-19.

15 Chobanian AV, Bakris GL, Black HR, Cushman WC, Green LA, Izzo JL Jr, et al.; National High Blood Pressure Education Program Coordinating Committee. The Seventh Report of the Joint National Committee on Prevention, Detection, Evaluation, and Treatment of High Blood Pressure: the JNC 7 Report. JAMA. 2003 May;289(19):2560-72.

16 O’Meara JG, Kardia SL, Armon JJ, Brown CA, Boerwinkle E, Turner ST. Ethnic and sex differences in the prevalence, treatment, and control of dyslipidemia among hypertensive adults in the GENOA study. Arch Intern Med. 2004 Jun;164(12):1313-8.
17 Osuji CU, Omejua EG, Onwubuya EI, Ahaneku GI. Serum lipid profile of newly diagnosed hypertensive patients in Nnewi, SouthEast Nigeria. Int J Hypertens. 2012;2012: 710486.

18 Gebrie A, Gnanasekaran N, Menon M, Sisay M, Zegeye A. Evaluation of lipid profiles and hematological parameters in hypertensive patients: a laboratory-based cross-sectional study. SAGE Open Med. 2018;6:1-11.

19 Akintunde AA, Ayodele EO, Akinwusi OP, Opadijo GO. Dyslipidemia among newly diagnosed hypertensives: pattern and clinical correlates. J Natl Med Assoc. 2010 May; 102(5):403-7.

20 Adamu UG, Okuku GA, Oladele CO, Abdullahi A, Oduh JI, Fasae AJ. Serum lipid profile and correlates in newly presenting Nigerians with arterial hypertension. Vasc Health Risk Manag. 2013;9:763-8.

21 Ericsson S, Eriksson M, Vitols S, Einarsson K, Berglund L, Angelin B. Influence of age on the metabolism of plasma low density lipoproteins in healthy males. J Clin Invest. $1991 \mathrm{Feb}$ 87(2):591-6.
22 Bachorik PS, Lovejoy KL, Carroll MD, Johnson CL. Apolipoprotein B and AI distributions in the United States, 1988-1991: results of the National Health and Nutrition Examination Survey III (NHANES III). Clin Chem. 1997 Dec;43(12):2364-78.

23 Wang X, Magkos F, Mittendorfer B. Sex differences in lipid and lipoprotein metabolism: it's not just about sex hormones. J Clin Endocrinol Metab. 2011 Apr;96(4):885-93.

24 Michael OA, Bimbola FM, Rotimi O. The relationship between measures of obesity and atherogenic lipids among Nigerians with hypertension. Malawi Med J. 2019 Sep;31(3): 193-7.

25 Okpara IC, Adediran OS. Dyslipidemia and its relationship with different anthropometric measures in Nigerian adults. IOSR J Dent Med Sci. 2013;9(3):07-12.

26 Onwubuya EI, Anisiuba BC, Osuji CU, Ahaneku JE. Changes in lipids and lipoprotein indices in relation to the severity of hypertension in newly diagnosed hypertensive Nigerians. ISRN Cardiol. 2012;2012:972341.

27 De Oliveira E Silva ER, Foster D, McGee Harper M, Seidman CE, Smith JD, Breslow JL, et al. Alcohol consumption raises HDL cholesterol levels by increasing the transport rate of apolipoproteins A-I and A-II. Circulation. 2000 Nov; 102(19):2347-52. 